\title{
A key role for an impaired detoxification mechanism in the etiology and severity of autism spectrum disorders
}

\author{
Altaf Alabdalii, Laila Al-Ayadhi, ${ }^{2,3,4}$ and Afaf El-Ansary ${ }^{1,2,3,5^{*}}$
}

\begin{abstract}
Background: Autism Spectrum Disorders (ASD) is a syndrome with a number of etiologies and different mechanisms that lead to abnormal development. The identification of autism biomarkers in patients with different degrees of clinical presentation (i.e., mild, moderate and severe) will give greater insight into the pathogenesis of this disease and will enable effective early diagnostic strategies and treatments for this disorder.

Methods: In this study, the concentration of two toxic heavy metals, lead (Pb) and mercury ( $\mathrm{Hg})$, were measured in red blood cells, while glutathione-s-transferase (GST) and vitamin E, as enzymatic and non-enzymatic antioxidants, respectively, were measured in the plasma of subgroups of autistic patients with different Social Responsiveness Scale (SRS) and Childhood Autism Rating Scale (CARS) scores. The results were compared to age- and gender-matched healthy controls.

Results: The obtained data showed that the patients with autism spectrum disorder had significantly higher Pb and Hg levels and lower GST activity and vitamin E concentrations compared with the controls. The levels of heavy metals $(\mathrm{Hg}$ and $\mathrm{Pb}), \mathrm{GST}$ and vitamin $\mathrm{E}$ were correlated with the severity of the social and cognitive impairment measures (SRS and CARS). Receiver Operating Characteristics (ROC) analysis and predictiveness curves indicated that the four parameters show satisfactory sensitivity, very high specificity and excellent predictiveness. Multiple regression analyses confirmed that higher levels of $\mathrm{Hg}$ and Pb, together with lower levels of GST and vitamin E, can be used to predict social and cognitive impairment in patients with autism spectrum disorders.

Conclusion: This study confirms earlier studies that implicate toxic metal accumulation as a consequence of impaired detoxification in autism and provides insight into the etiological mechanism of autism.
\end{abstract}

Keywords: Autism Spectrum Disorder, Social Responsiveness Scale (SRS), Childhood Autism Rating Scale (CARS), Lead, Mercury, Glutathione-s-transferase, Vitamin E

\section{Introduction}

Autism is characterized by a set of repetitious behavior in combination with social, cognitive and communication deficits [1]. An emerging hypothesis states that autism may result from a combination of genetic susceptibility and exposure to environmental toxins at critical periods during brain development [2]. Neurotoxins and associated inflammation of the brain tissue are often the focus of therapies for patients with autism. However, if

\footnotetext{
*Correspondence: elansary@ksu.edu.sa

'Biochemistry Department, Science College, King Saud University, P.O box 22452, Zip code 11495 Riyadh, Saudi Arabia

${ }^{2}$ Autism Research and Treatment Center, Riyadh, Saudi Arabia

Full list of author information is available at the end of the article
}

body detoxification is impaired, neuroinflammation will not efficiently improve unless the overall body issues are addressed. Xenobiotics are neurotoxins of external origin, such as chemicals and pollutants in the air, water, food additives and drugs, that can dramatically alter the health of the child. An efficient three-phase mechanism is involved in detoxifying these toxins [3]; however, several factors play a role in modulating this mechanism. For example, age, gender and diet are among the various biological and non-biological factors that modulate individual susceptibility. Additionally, genetic variability plays a critical role in individual susceptibility because variable detoxifier phenotypes result from mutations in 
the same gene. These range from individuals with regular enzyme and detoxification functions to poor metabolizers with low or no enzyme activity $[4,5]$.

Glutathione-S-transferase (GST) functions in the detoxification of xenobiotics, drugs, toxins, and metabolites and is also involved in the regulation of mitogen-activated protein kinases, which are important during differentiation and development. $\mathrm{Hg}$ and $\mathrm{Pb}$, however, are two well-known toxicants that have toxic effects on the body, with the brain being the most susceptible target organ. Exposure to $\mathrm{Hg}$ and $\mathrm{Pb}$ during pregnancy and early childhood can cause neurodevelopmental impairment and subclinical brain dysfunction because both heavy metals can cross the placenta and the blood-brain-barrier [6]. In the brain, these metals can affect critical developmental processes, including cell proliferation, migration, differentiation, synaptogenesis, myelination, and apoptosis [6].

It is well documented that patients with ASD have many statistically significant differences in their nutritional and metabolic status compared with those who do not have ASD. Some of these biomarkers are indicative of vitamin E insufficiency, increased oxidative stress, and poor detoxification and are associated with the severity of the disorder [7-10]. A recent study found that impaired xenobiotic detoxification is correlated with increased gut permeability (leaky gut) and neuroinflammation, two accepted pathological phenomena in ASD [3].

These findings prompted us to search for biochemical correlations related to the detoxification mechanism and neurobiological processes and the severity and social functioning of patients with ASD measured by the CARS and SRS. We selected $\mathrm{Hg}$ and $\mathrm{Pb}$ as two environmental toxicants involved in the etiology of ASD, together with GST and vitamin E as enzymatic and non-enzymatic antioxidants with high activity in terminating lipid peroxidation and environmental toxicity. We hypothesized that confirming the relationship between impaired detoxification mechanism and severity of ASD could enhance efforts at early prevention, diagnosis, and intervention and, thus, may play a role in decreasing the prevalence of autism.

\section{Material and methods}

\section{Subjects}

This cross-sectional study was conducted on 52 autistic male children who were recruited from the Autism Research and Treatment Center, Faculty of Medicine, King Saud University, Riyadh, Saudi Arabia. Of these children, 40 were nonverbal, and 12 were verbal. Their ages ranged between 3 and 12 years (mean $\mathrm{SD}=7.0 \pm 2.34$ years). The control group was comprised of 30 age- and sex-matched apparently healthy children with a mean age of $7.2 \pm$ 2.14 years. The patients fulfilled the diagnostic criteria of autism described in the 4th edition of the Diagnostic and
Statistical Manual of Mental Disorders. The controls were normally developing, healthy children who were unrelated to the autistic subjects and did not have any of the exclusion criteria. The control children were the healthy older siblings of healthy infants who were attending the Well Baby Clinic at King Khalid University Hospital for routine check-ups of their growth parameters. They had no clinical indications of infectious diseases or neuropsychiatric disorders. All participants had normal results for urine analysis and sedimentation rate. The local Ethical Committee of the Faculty of Medicine, King Saud University, Riyadh, Saudi Arabia, approved this study. In addition, an informed written consent of participation for this study was signed by the parents or the legal guardians of the investigated subjects, according to the Helsinki principles. The selected sample of participants was based on how convenient and readily available the group of participants was (i.e., convenience sampling). Participants were excluded from the study if they had a diagnosis of fragile $\mathrm{X}$ syndrome, epileptic seizures, obsessive-compulsive disorder, affective disorders, or any additional psychiatric or neurological diagnoses.

\section{Measurement of Autism severity scales (CARS and SRS)}

The Childhood Autism Rating Scale (CARS) score, which is a measurement of the severity of the disease, rates the child on a scale from one to four in each of fifteen areas (relating to people's emotional response; imitation; body use; object use; listening response; fear or nervousness; verbal communication; non-verbal communication; activity level; level and reliability of intellectual response; adaptation to change; visual response; taste, smell and touch response and general impressions). According to the scale, children who scored 30-36 had mild to moderate autism $(\mathrm{n}=23)$, while those with scores ranging between 37 and 60 points had severe autism $(n=27)[11,12]$.

To calculate a score for the Social Responsiveness Scale, a questionnaire was completed in 15 to 20 minutes. A total score of 76 or higher was considered severe and strongly associated with a clinical diagnosis of autistic disorder. A score of 60-75 was interpreted as falling in the mild to moderate range of social impairment [13].

\section{Sample collection}

After an overnight fast, 10-ml blood samples, from both groups of children, were collected in test tubes containing sodium heparin as an anticoagulant. The tubes were centrifuged at $3500 \mathrm{rpm}$ for 15 minutes at room temperature. Plasma and red blood cells were separated and stored at $80^{\circ} \mathrm{C}$ until required for analysis.

\section{Biochemical analysis}

Plasma is a complex bodily fluid containing proteins, peptides, lipids and metabolites and can reflect physiological 
activity and pathology in various body organs, including the CNS. In humans, approximately $500 \mathrm{ml}$ of CSF is absorbed into the blood daily, making blood a suitable source of biomarkers of neurodegenerative or neurodevelopmental diseases [14]. All biochemical assays were performed in duplicate and blinded to the clinical status of the participants.

\section{1- Measurement of mercury}

The concentration of inorganic mercury $(\mathrm{Hg})$ in red blood cells was determined by the method described by Magos [15] using a flameless atomic-absorption method. The red blood cells were diluted with saline to $20 \mathrm{ml}$, followed by the addition of $1 \mathrm{ml}$ of a $1 \%$ cysteine solution, $10 \mathrm{ml}$ of $8 \mathrm{M} \mathrm{H}_{2} \mathrm{SO}_{4}$ and $1 \mathrm{ml}$ of $\mathrm{SnCl}_{2}(100 \mathrm{mg} / \mathrm{ml})$. The sample was subjected to immediate aeration at a constant rate of $2.5 \mathrm{l} / \mathrm{min}$ through the reaction vessel, and $20 \mathrm{ml}$ of a $45 \%$ $\mathrm{NaOH}$ was added. The $\mathrm{SnCl}_{2}$ reagent was used to release all of the inorganic mercury from the samples. Aeration was discontinued after the recorder pen had settled back to within a few chart divisions (2 or 3 ) of its original baseline, which was approximately 1 to $1.5 \mathrm{~min}$, depending on the actual aeration rate. The concentration of mercury was measured using a flameless atomic-absorption method, and the concentration was calculated using a standard calibration curve prepared using a standard $\mathrm{Hg}$ concentration.

\section{2- Measurement of $\mathrm{Pb}$}

Lead levels were measured in red blood cells using adaptations of the methods described by Miller et al. [16] and Parsons and Slavin [17]. Briefly, RBCs $(0.1 \mathrm{ml})$ were resuspended and digested in $3.9 \mathrm{ml}$ of $0.5 \mathrm{~N}$ nitric acid. Lead quantification was based on the measurement of light absorbed at $283.3 \mathrm{~nm}$ by the ground-state atoms of $\mathrm{Pb}$ from a hollow cathode lamp $(\mathrm{HCl})$ source.

\section{3- Determination of glutathione-S-transferase activity (GST)} GST activity was assessed in the plasma using an assay kit (Biovision, USA). The kit is based on a GST-catalyzed reaction between GSH and the GST substrate, CDNB (1-chloro-2, 4-dinitrobenzene). The GST-catalyzed formation

Table 1 Mercury $(\mu \mathrm{g} / \mathrm{L})$, lead $(\mu \mathrm{g} / \mathrm{dl})$, GST $(\mu \mathrm{mol} / \mathrm{l})$ and vitamin E (nmol/L) levels in the control \& autistic groups

\begin{tabular}{|c|c|c|c|c|c|}
\hline Parameters & Group & $\mathbf{N}$ & Mean \pm S.D. & $P$ value $^{a}$ & $P$ value $^{\mathrm{b}}$ \\
\hline \multirow[t]{6}{*}{ Mercury $(\mu \mathrm{g} / \mathrm{L})$} & Control & 32 & $5.12 \pm 0.83$ & & \\
\hline & Patients with autism & 58 & $6.99 \pm 0.94$ & & 0.001 \\
\hline & Autism (mild to moderate in CARS) & 29 & $6.49 \pm 0.65$ & \multirow{2}{*}{0.042} & 0.001 \\
\hline & Autism (severe in CARS) & 28 & $7.31 \pm 0.49$ & & 0.001 \\
\hline & Autism (mild to moderate in SRS) & 22 & $7.02 \pm 0.85$ & \multirow{2}{*}{0.050} & 0.001 \\
\hline & Autism (severe in SRS) & 22 & $7.46 \pm 0.59$ & & 0.001 \\
\hline \multirow[t]{6}{*}{ Lead $(\mu \mathrm{g} / \mathrm{dl})$} & Control & 32 & $4.73 \pm 0.67$ & & \\
\hline & Patients with autism & 58 & $6.79 \pm 0.97$ & & 0.001 \\
\hline & Autism (mild to moderate in CARS) & 29 & $6.34 \pm 0.82$ & \multirow[t]{2}{*}{0.041} & 0.001 \\
\hline & Autism (severe in CARS) & 28 & $6.80 \pm 0.83$ & & 0.001 \\
\hline & Autism (mild to moderate in SRS) & 22 & $6.42 \pm 0.84$ & \multirow[t]{2}{*}{0.040} & 0.001 \\
\hline & Autism (severe in SRS) & 22 & $6.95 \pm 0.81$ & & 0.001 \\
\hline \multirow[t]{6}{*}{ GST $(\mu \mathrm{mol} / \mathrm{min} / \mathrm{ml})$} & Control & 30 & $0.61 \pm 0.17$ & & \\
\hline & Patients with autism & 30 & $0.30 \pm 0.08$ & & 0.001 \\
\hline & Autism (mild to moderate in CARS) & 18 & $0.31 \pm 0.07$ & \multirow{2}{*}{0.043} & 0.001 \\
\hline & Autism (severe in CARS) & 12 & $0.26 \pm 0.07$ & & 0.001 \\
\hline & Autism (mild to moderate in SRS) & 8 & $0.32 \pm 0.07$ & \multirow{2}{*}{0.027} & 0.001 \\
\hline & Autism (severe in SRS) & 18 & $0.25 \pm 0.06$ & & 0.001 \\
\hline \multirow[t]{6}{*}{ Vitamin E (nmol/L) } & Control & 27 & $25.44 \pm 2.62$ & & \\
\hline & Patients with autism & 28 & $14.45 \pm 2.28$ & & 0.001 \\
\hline & Autism (mild to moderate in CARS) & 11 & $14.56 \pm 1.58$ & \multirow{2}{*}{0.048} & 0.001 \\
\hline & Autism (severe in CARS) & 17 & $13.36 \pm 1.47$ & & 0.001 \\
\hline & Autism (mild to moderate in SRS) & 11 & $14.85 \pm 1.36$ & \multirow{2}{*}{0.044} & 0.001 \\
\hline & Autism (severe in SRS) & 12 & $13.35 \pm 1.14$ & & 0.001 \\
\hline
\end{tabular}

\footnotetext{
${ }^{\mathrm{a}} P$ value between mild to moderate and severe in CARS and SRS
}

${ }^{\mathrm{b}} P$ value between control and autistic groups. 
Figure 1 Mean levels of A) mercury $(\mu \mathrm{g} / \mathrm{L}), \mathrm{B})$ lead $(\mu \mathrm{g} / \mathrm{L})$, C) GST ( $\mu \mathrm{mol} / \mathrm{min} / \mathrm{ml})$ and D) vitamin E (nmol/L) of the autistic groups compared with age- and sex-matched controls. The mean value for each group is designated by a line.

of GS-DNB produces a dinitrophenyl thioether, which can be detected by a spectrophotometer at $340 \mathrm{~nm}$. GST activity was expressed as $\mu \mathrm{mole} / \mathrm{min} / \mathrm{ml}$ plasma.

\section{4- Vitamin E assay (a -tocopherol)}

Plasma vitamin E was assessed using high pressure liquid chromatography (HPLC) as described by Driskell et al. [18]. The separation via HPLC follows an isocratic method at $30^{\circ} \mathrm{C}$ using a "reversed phase" column; one run lasts 15 minutes. The detection was performed with a UV detector at $290 \mathrm{~nm}$. The quantification was performed with the delivered standard solution; the concentration was calculated via the integration of the peak areas in the internal standard calibration mode.

\section{Statistical analysis}

The Statistical Package for the Social Sciences (SPSS) computer program was used. The results were expressed as the mean $\pm \mathrm{SD}$, and all statistical comparisons were made by means of independent t-tests, with $P \leq 0.05$ considered as significant. ROC analysis was performed. Areas under the curve and cut off values were selected by the program. The degree of specificity and sensitivity were calculated. Moreover, the predictiveness diagrams of the four measured parameters were drawn using a Biostat 16 computer program in which the $x$ axis represents percentile rank of the biomarker, the $y$ axis represents the probability of identifying the disease and the horizontal line is the prevalence of the disease. Enter and stepwise multiple regression analyses were performed using CARS and SRS as two dependent variables and $\mathrm{Hg}, \mathrm{Pb}, \mathrm{GST}$ and vitamin $\mathrm{E}$ as independent variables.

\section{Results}

Table 1 and Figure 1 present the mean $\pm \mathrm{SD}$ of $\mathrm{Hg}, \mathrm{Pb}$ and plasma GST and vitamin E levels in RBCs of the control, severe autistic and mild-moderate autistic patients with different CARS and SRS scores. Mercury and $\mathrm{Pb}$ were significantly elevated in the autistic patients compared with the controls, with increases of $36.58 \%$ and $43.34 \%$, respectively. GST and vitamin E levels decreased by $50.71 \%$ and $43.18 \%$ percent, respectively (Figure 2).

Table 2 and Figure 3 show the ROC analysis of the four measured parameters. The area under the curve (AUC), specificity and sensitivity are illustrated. Figure 4 shows the predictiveness curves of the four measured parameters exhibiting high and low risk in relation to the prevalence of autism in Saudi Arabia. 

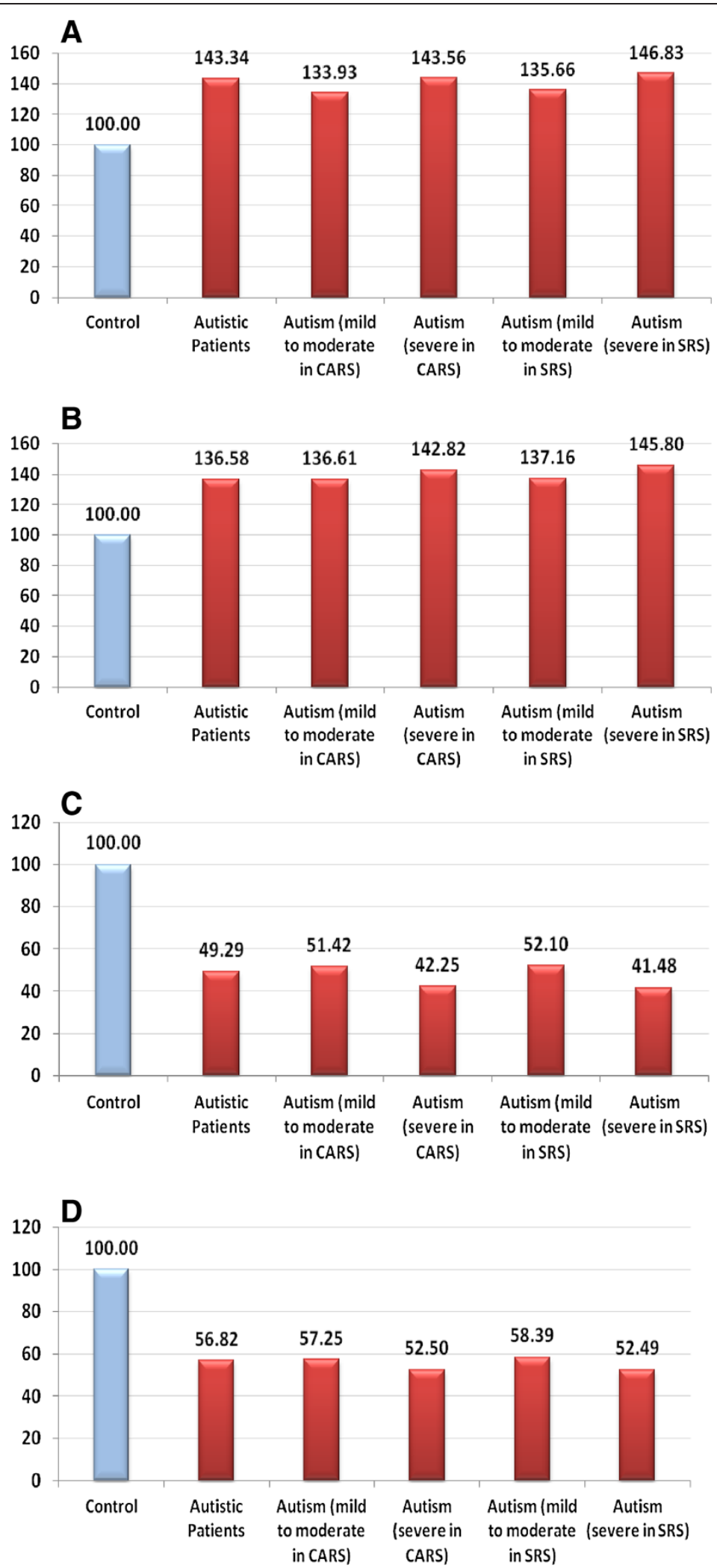

Figure 2 Percentage change of A) mercury, B) lead, C) GST and D) vitamin E in the autistic group relative to the control group, which is represented as $100 \%$. 
Table 2 ROC-curve of mercury $(\mu \mathrm{g} / \mathrm{L})$, lead $(\mu \mathrm{g} / \mathrm{dl})$, GST ( $\mu \mathrm{mol} / \mathrm{l})$ and vitamin $\mathrm{E}(\mathrm{nmol} / \mathrm{L})$ levels in the autistic groups

\begin{tabular}{|c|c|c|c|c|c|c|}
\hline \multirow{2}{*}{ Parameters } & & \multirow{2}{*}{$\begin{array}{l}\text { Autistic } \\
\text { patients }\end{array}$} & \multicolumn{2}{|c|}{ CARS } & \multicolumn{2}{|c|}{ SRS } \\
\hline & & & Mild to moderate & Severe & Mild to moderate & Severe \\
\hline \multirow[t]{4}{*}{ Mercury } & Area under the curve & 0.926 & 0.961 & 1.000 & 0.935 & 0.997 \\
\hline & Best cutoff value & 6.018 & 6.018 & 6.316 & 6.105 & 6.346 \\
\hline & Sensitivity $\%$ & $84.5 \%$ & $93.1 \%$ & $100.0 \%$ & $86.4 \%$ & $95.5 \%$ \\
\hline & Specificity \% & $93.8 \%$ & $93.8 \%$ & $100.0 \%$ & $96.9 \%$ & $100.0 \%$ \\
\hline \multirow[t]{4}{*}{ Lead } & Area under the curve & 0.953 & 0.917 & 0.980 & 0.923 & 0.980 \\
\hline & Best cutoff value & 5.586 & 5.590 & 6.132 & 6.132 & 6.321 \\
\hline & Sensitivity \% & $89.7 \%$ & $79.3 \%$ & $89.3 \%$ & $72.7 \%$ & $86.4 \%$ \\
\hline & Specificity \% & $87.5 \%$ & $87.5 \%$ & $96.9 \%$ & $96.9 \%$ & $100.0 \%$ \\
\hline \multirow[t]{4}{*}{ GST } & Area under the curve & 0.980 & 0.974 & 1.000 & 0.983 & 1.000 \\
\hline & Best cutoff value & 0.443 & 0.443 & 0.320 & 0.443 & 0.320 \\
\hline & Sensitivity \% & $100.0 \%$ & $100.0 \%$ & $100.0 \%$ & $100.0 \%$ & $100.0 \%$ \\
\hline & Specificity \% & $93.3 \%$ & $93.3 \%$ & $100.0 \%$ & $93.3 \%$ & $100.0 \%$ \\
\hline \multirow[t]{4}{*}{ Vitamin E } & Area under the curve & 0.999 & 1.000 & 1.000 & 1.000 & 1.000 \\
\hline & Best cutoff value & 19.254 & 18.718 & 18.089 & 18.718 & 17.953 \\
\hline & Sensitivity \% & $96.4 \%$ & $100.0 \%$ & $100.0 \%$ & $100.0 \%$ & $100.0 \%$ \\
\hline & Specificity \% & $100.0 \%$ & $100.0 \%$ & $100.0 \%$ & $100.0 \%$ & $100.0 \%$ \\
\hline
\end{tabular}

Table 3 shows positive and negative correlations between the four measured parameters in this study. The results showed that while $\mathrm{Pb}$ and $\mathrm{Hg}$ were positively correlated with each other, both metals were negatively correlated with GST and vitamin E as enzymatic and non-enzymatic detoxifiers.

Tables 4, 5, 6 and 7 show multiple regression analysis results using the Enter method (Tables 4 \& 6) and Stepwise method (Tables $5 \&$ 7) for the CARS and SRS scores as two dependent variables, respectively. The value of $R^{2}$ shows that 0.56 or $56 \%$ of the variance of the CARS scores and almost $40 \%$ of the variance of the SRS scores were explained by the regression of the four measured parameters, with GST and vitamin E being more predictive (stepwise regression as presented in Tables 5 \& 7).

\section{Discussion}

Exposure to even low levels of lead $(\mathrm{Pb})$ early in life has adverse effects on a variety of cognitive and behavioral functions and neurochemical systems, resulting in deficits in learning, memory and attention that may persist into adulthood [19-22]. Persistent effects of Pb exposure early in life can produce changes that arise from physiological re-programming [23]. In this study, there was a significant increase in $\mathrm{Pb}$ levels in patients with ASD compared with the control group, coupled with a correlation between $\mathrm{Pb}$ concentration and the severity of SRS and CARS scores. These observations support a recent study on patients with ASD by Schneider et al. (2013) [24], who suggested potential epigenetic effects of developmental $\mathrm{Pb}$ exposure on DNA methylation. These effects were mediated at least partially through the dysregulation of methyltransferases as multiple forms of proteins, at least some of which are potentially involved in cognition [25], and the resulting abnormalities were recorded in patients with ASD [26].

The reported elevation of $\mathrm{Hg}$ and $\mathrm{Pb}$ in the RBCs of patients with ASD compared with the control subjects (Table 1 and Figure 1A\&B) can be related to and support a previous study by Al-Yafee et al. [27] in which Saudi patients with ASD were described as poor detoxifiers with a lower GSH/GSSG ratio and remarkably less active GST and thioredoxin reductase as markers of the detoxification mechanism. It is well known that GSH and GST are both critical for the detoxification of mercury [28]. While GSH carries $\mathrm{Hg}$ through biliary transport for excretion, $\mathrm{Hg}^{2+}$ rapidly oxidizes glutathione [28]. This observation is correlated with the previous work of Al-Gadani et al. [8] who reported lower GSH in the plasma of Saudi patients with ASD. Additionally, the increase of $\mathrm{Hg}$ and $\mathrm{Pb}$ recorded in this study is consistent with previous studies. For example, Blaurock-Busch et al. [29] found a significant increase of both toxicants in the hair of autistic children compared with non-autistic children. This observation may indicate an impaired detoxification mechanism as a risk factor that significantly contributes to the etiology of autism. The exposure of patients with ASD in early childhood to mercury vapor, methylmercury and ethylmercury may 


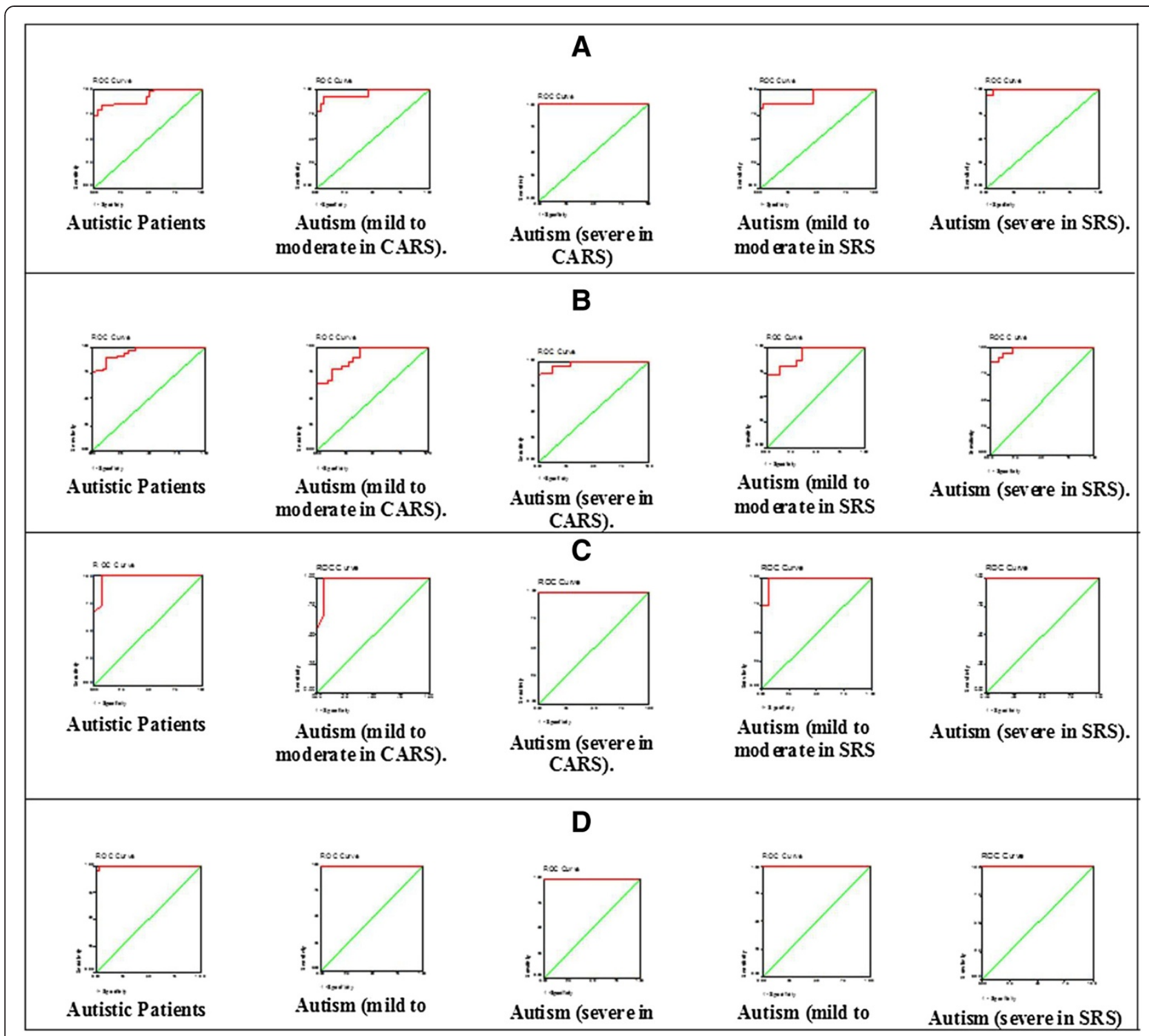

Figure 3 ROC-curves for A) mercury, B) lead, C) GST and D) vitamin E in the autistic groups.

occur through dental amalgams, fish intake and vaccinations [30-32].

Furthermore, in this study, remarkably higher levels of $\mathrm{Hg}$ and $\mathrm{Pb}$ were recorded in patients with severe social and cognition impairment (SRS \& CARS) compared with those with mild-moderate abnormalities. This observation suggests that heavy metal toxicity is closely related to the pathophysiology of autism. This outcome does not concur with a study by Elsheshtawy et al. in which $\mathrm{Hg}$, but not $\mathrm{Pb}$, was found in the hair of autistic patients as a biochemical correlate to disease severity (CARS) [33]. However, our results are consistent with the recent work of Adams et al. [34] who reported that children with autism have higher average levels of several toxic metals, among which $\mathrm{Hg}$ and $\mathrm{Pb}$ are strongly associated with variations in the severity of the disorder. However, in their study, Adams et al. found a nonsignificant difference of $\mathrm{Hg}$ in children with autism vs. neurotypical children. This could be attributed to differences in geographic exposure to mercury (Saudi Arabia vs. Arizona). Patients with autism are poor detoxifiers (i.e., unable to detoxify mercury when it reaches a certain level) [27]. Therefore, this could indicate a higher rate of exposure to $\mathrm{Hg}$ in the Saudi population compared with the population in Arizona.

Face recognition is a core deficit of social impairment in autism. A number of studies indicate that norepinephrine (NE) and dopamine (DA) modulate and reduce behavioral responses to changes in the social environment $[35,36]$. In addition, serotonin $(5 \mathrm{HT})$ transporter 


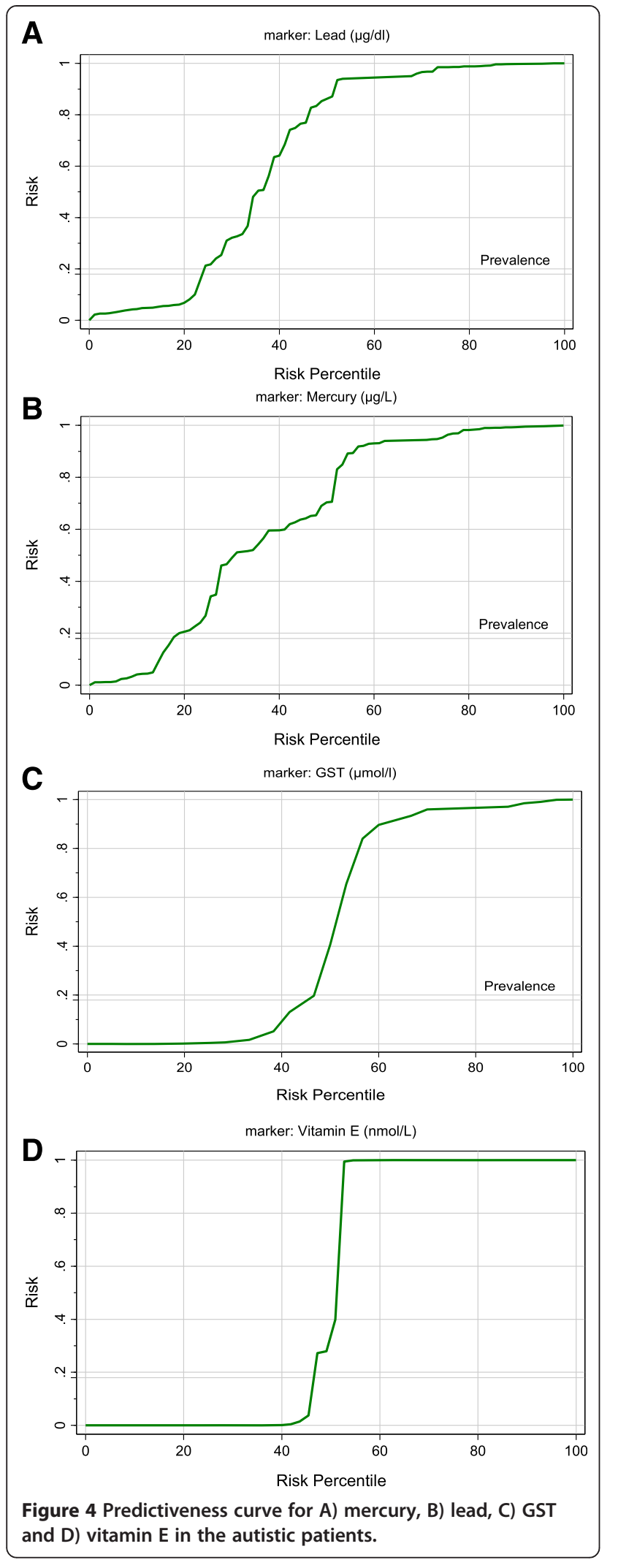

Table 3 Statistically significant Pearson's correlation between the four measured parameters

\begin{tabular}{lccc}
\hline Parameters & R (Person correlation) & Sig. & \\
\hline GST $\sim$ Mercury & -0.613 & $0.001^{* *}$ & $\mathrm{~N}^{\mathrm{b}}$ \\
GST $\sim$ Lead & -0.588 & $0.001^{* *}$ & $\mathrm{~N}^{\mathrm{b}}$ \\
GST $\sim$ Vitamin E & 0.696 & $0.001^{* *}$ & $\mathrm{P}^{\mathrm{a}}$ \\
Mercury Lead & 0.761 & $0.001^{* *}$ & $\mathrm{P}^{\mathrm{a}}$ \\
Mercury $\sim$ Vitamin E & -0.710 & $0.001^{* *}$ & $\mathrm{~N}^{\mathrm{b}}$ \\
Lead $\sim$ Vitamin E & -0.715 & $0.001^{* *}$ & $\mathrm{~N}^{\mathrm{b}}$
\end{tabular}

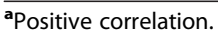

bNegative correlation.

${ }^{* *}$ Correlation is significant at the 0.01 level (2-tailed).

binding appears to be reduced in certain brain regions known to play an important role in social cognition and behavior [37], and 5HT binding potential is negatively correlated with social impairment. Therefore, recording $\mathrm{Pb}$ as a correlate to severity of SRS and CARS scores in the present study is consistent with the recent findings of El-Ansary et al. [38] in which a positive association was observed between chronic $\mathrm{Pb}$ toxicity and lower levels of neurotransmitters as markers of neurologic injury in autistic brains in a Saudi population. Alternately, the biochemical correlation between $\mathrm{Pb}$ and the severity of autism is in agreement with other studies. SzkupJabłońska et al. [39] and Blaurock-Busch et al. [40] reported a significant correlation between $\mathrm{Pb}$ and fear, nervousness, verbal and nonverbal communication, social activity level, and consistency of intellectual response. Moreover, the positive correlation between elevated $\mathrm{Pb}$ toxicity and both autistic scales could be supported by the fact that $\mathrm{Pb}$ exposure affects multiple health outcomes and physiological systems [41]. These include behavioral/ cognitive/IQ effects, nerve conductive effects, hearing loss, reproduction and development effects and death from encephalopathy. Long-term trends in population exposure to $\mathrm{Pb}$ (indexed through use of leaded petrol and paint) were remarkably consistent with the link between IQ and social behavior [42].

The significant reduction in plasma GST in Saudi patients with autism compared with controls is documented in this study (Table 1 and Figure 1C\&D). This

Table 4 Multiple regression using the enter method for CARS as a dependent variable

\begin{tabular}{|c|c|c|c|c|c|}
\hline \multirow[t]{2}{*}{ Model } & \multirow[t]{2}{*}{ Beta } & \multirow[t]{2}{*}{$P$ value } & \multirow[t]{2}{*}{ Adjusted $\mathrm{R}^{2}$} & \multicolumn{2}{|c|}{ Model } \\
\hline & & & & $F$ value & $P$ value \\
\hline (Constant) & 3.038 & 0.005 & \multirow{5}{*}{0.564} & \multirow{5}{*}{25.907} & \multirow{5}{*}{0.001} \\
\hline Mercury $(\mu \mathrm{g} / \mathrm{L})$ & 0.161 & 0.139 & & & \\
\hline Lead ( $\mu \mathrm{g} / \mathrm{dl})$ & 0.004 & 0.971 & & & \\
\hline GST $(\mu \mathrm{mol} / \mathrm{l})$ & -1.159 & 0.081 & & & \\
\hline $\begin{array}{l}\text { Vitamin E } \\
(\mathrm{nmol} / \mathrm{L})\end{array}$ & -0.082 & 0.002 & & & \\
\hline
\end{tabular}


Table 5 Multiple regression using the stepwise method for CARS as a dependent variable

\begin{tabular}{lccccc}
\hline Model & Beta & P value & Adjusted R $^{2}$ & \multicolumn{2}{c}{ Model } \\
\cline { 3 - 5 } & & & & F value & P value \\
\hline (Constant) & 4.517 & 0.001 & & & \\
$\begin{array}{l}\text { Vitamin E } \\
(\mathrm{nmol} / \mathrm{L})\end{array}$ & -0.103 & 0.001 & 0.560 & 49.909 & 0.001 \\
$\mathrm{GST}(\mu \mathrm{mol} / \mathrm{l})$ & -1.383 & 0.035 & & & \\
\hline
\end{tabular}

could be related to the significant depletion of GSH as a substrate of GST in the plasma of patients with ASD compared with control subjects $[8,43,44]$. The reduction in this essential detoxifying enzyme can explain the poor detoxification in patients with ASD, leading to the $\mathrm{Hg}$ and $\mathrm{Pb}$ toxicity discussed above.

In our study, there was an inverse relationship between decreased levels of plasma GST and the severity of autism, as measured by the SRS and CARS. Severely autistic cases had a remarkably lower GST activity compared to mildmoderate cases of autism. These outcomes concur with Geier et al. [45], who also found a significant inverse relationship between blood GSH levels and autism severity measured with the CARS. Mercury aggravates impaired glutathione synthesis by depleting glutathione in lymphocytes and monocytes, leading to an increased risk of immuno and cytotoxic effects.

Although, the roles and importance of various forms of vitamin E are still unclear [46], it has been suggested that the most important function of $\alpha$-tocopherol is as a signaling molecule playing an important role in protecting neurons from damage [47]. As an antioxidant, vitamin E may prevent or reduce the propagation of free radicals, which are associated with physical decline, in the human body. This may help reduce muscle or DNA damage and prevent the development of pathological conditions, such as autism [48]. Table 1 and Figure 1D demonstrate the significantly reduced levels of vitamin $\mathrm{E}$ in the plasma of patients with ASD compared with the control group. Herndon et al. [49] also found decreased vitamin E levels in autistic patients. The brain contains high levels of oxidizable lipids that must be protected by

Table 6 Multiple regression using the enter method for SRS as a dependent variable

\begin{tabular}{|c|c|c|c|c|c|}
\hline \multirow[t]{2}{*}{ Model } & \multirow[t]{2}{*}{ Beta } & \multirow[t]{2}{*}{$P$ value } & \multirow[t]{2}{*}{ Adjusted $\mathrm{R}^{2}$} & \multicolumn{2}{|c|}{ Model } \\
\hline & & & & F value & $P$ value \\
\hline (Constant) & 4.844 & 0.028 & \multirow{5}{*}{0.391} & \multirow{5}{*}{12.867} & \multirow{5}{*}{0.001} \\
\hline Mercury $(\mu g / L)$ & 0.261 & 0.248 & & & \\
\hline Lead ( $\mu \mathrm{g} / \mathrm{dl})$ & 0.117 & 0.575 & & & \\
\hline GST $(\mu \mathrm{mol} / \mathrm{l})$ & -1.890 & 0.185 & & & \\
\hline $\begin{array}{l}\text { Vitamin E } \\
(\mathrm{nmol} / \mathrm{L})\end{array}$ & -0.134 & 0.012 & & & \\
\hline
\end{tabular}

Table 7 Multiple regression using the stepwise method for SRS as a dependent variable

\begin{tabular}{lccccc}
\hline Model & Beta & P value & Adjusted $\mathbf{R}^{2}$ & \multicolumn{2}{c}{ Model } \\
\cline { 5 - 6 } & & & & F value & P value \\
\hline (Constant) & 6.298 & 0.001 & & & \\
$\begin{array}{l}\text { Vitamin } E \\
(\mathrm{nmol} / \mathrm{L})\end{array}$ & -0.202 & 0.001 & 0.384 & 47.167 & 0.001 \\
\hline
\end{tabular}

antioxidants; hence, the supplementation of ASD patients with vitamin $\mathrm{E}$ as a major lipophilic antioxidant could be helpful $[7,50]$. The highly significant correlation between vitamin $\mathrm{E}$ depletion and severity of autism, as measured by the SRS and CARS, supports its critical role in protecting against the toxic effects of $\mathrm{Pb}$ and $\mathrm{Hg}$. This is consistent with a previous report by Adams et al. [7] that showed a significant association between vitamin E insufficiency and the severity of the Autism Scale (SAS).

ROC analyses of $\mathrm{Pb}, \mathrm{Hg}, \mathrm{GST}$ and vitamin $\mathrm{E}$ are presented in Table 2 and Figure 3(A-D). All measured parameters demonstrated almost $100 \%$ sensitivity and very high specificity, which also confirmed the hypothesis that autistic patients are poor detoxifiers, unable to readily excrete toxic substances (e.g., $\mathrm{Hg}$ and $\mathrm{Pb}$ ), and suggests that reduced GST activity and depleted vitamin E are two critical factors related to poor detoxification.

Lead, Hg, GST and vitamin E show perfect predictiveness curves (Figure 4A-D). Excellent predictiveness curves for the four parameters reflect the possibility of using any of these parameters to follow up an antioxidant-related treatment strategy. A successful treatment could be followed through a remarkable elevation of plasma vitamin E, the activation of GST or both in autistic patients. Alternately, efficacious treatment could occur through a reduction in $\mathrm{Pb}$ and $\mathrm{Hg}$ levels. In addition, the relationship between vitamin E deficiency and the etiology of autism could be ascertained by the high specificity, sensitivity and AUC, as shown with the ROC analysis (Table 2).

The negative correlations between $\mathrm{Hg} \& \mathrm{~Pb}$ and vitamin E \& GST (Table 3) suggest the use of vitamin E as a nonenzymatic antioxidant in treating patients with autism. This suggestion is supported by the multiple regression analysis results (Tables 4, 5, 6 and 7), confirming that higher levels of $\mathrm{Hg}$ and $\mathrm{Pb}$, together with lower levels of GST and vitamin E, can be used to predict cognitive and social impairment with the regression of both antioxidant parameters, which is more related to abnormalities of both.

\section{Conclusion}

The high values of both sensitivity and specificity recorded for $\mathrm{Pb}, \mathrm{Hg}$, GST and vitamin $\mathrm{E}$, together with the 
good predictiveness curves; suggest that these can be used as biomarkers for measuring the severity of SRS and CARS scores in a Saudi population. This study confirmed the impaired antioxidant and detoxification mechanisms in Saudi autistic patients. Hence, early intervention through the supplementation of good quality and safe antioxidants, including vitamin E, carnosine and selenium, can be helpful in decreasing the burden of heavy metal toxicity. Vitamin E exists in eight different forms: four tocopherols and four tocotrienols. The measured form of vitamin E, $\alpha$-tocopherol, is one of the forms that regulate signal transduction pathways by mechanisms that are independent of its antioxidant properties, and its use as a supplement can be effective in reducing the toxicity burden in these patients. Autistic children who undergo intensive intervention have better social interaction than children who do not.

\section{Competing interests}

The author declares that they have no competing interest.

\section{Authors' contributions}

AA performed the practical work and co-drafted the manuscript. LA provided samples and participated in the diagnosis of the autistic samples. AE designed the study and drafted the manuscript. All authors have read and approved the final manuscript.

\section{Acknowledgments}

This research project was supported by a grant from the research center of the center for female scientific and medical colleges in King Saud University.

\section{Author details \\ ${ }^{1}$ Biochemistry Department, Science College, King Saud University, P.O box 22452, Zip code 11495 Riyadh, Saudi Arabia. ${ }^{2}$ Autism Research and Treatment Center, Riyadh, Saudi Arabia. ${ }^{3}$ Shaik AL-Amodi Autism Research Chair, King Saud University, Riyadh, Saudi Arabia. ${ }^{4}$ Department of Physiology, Faculty of Medicine, King Saud University, Riyadh, Saudi Arabia. ${ }^{5}$ Medicinal Chemistry Department, National Research Centre, Dokki, Cairo, Egypt.}

Received: 24 October 2013 Accepted: 15 April 2014

Published: 28 April 2014

\section{References}

1. American Psychiatric Association: Diagnostic and Statistical Manual of Mental Disorders (fourth, text revision ed.). Washington, DC: American Psychiatric Association; 2000.

2. Garrecht M, Austin DW: The plausibility of a role for mercury in the etiology of autism: a cellular perspective. Toxicol Environ Chem 2011, 93(5-6):1251-1273.

3. El-Ansary A: Detoxification mechanisms in autism spectrum disorders. OA Autism 2013, 1(2):19.

4. Koch L: Cancer: polymorphisms in detoxification genes increase in HMTC and match tumor phenotype. Nat Rev Endocrinol 2013, 9:128.

5. McFadden SA: Phenotypic variation in xenobiotic metabolism and adverse environmental response: focus on sulfur-dependent detoxification pathways. Toxicology 1996, 111(1-3):43-65.

6. Grandjean P, Landrigan P: Developmental neurotoxicity of industrial chemicals. Lancet 2006, 368:2167-2178.

7. Adams JB, Audhya T, McDonough-Means S, Rubin RA, Quig D, Geis E, Gehn E, Loresto M, Mitchell J, Atwood S, Barnhouse S, Lee W: Nutritional and metabolic status of children with autism vs. neurotypical children, and the association with autism severity. Nutr Metab 2011, 8:34.

8. Al-Gadani Y, El-Ansary A, Attas O, Al-Ayadhi L: Metabolic biomarkers related to oxidative stress and antioxidant status in Saudi autistic children. Clin Biochem 2009, 42:1032-1040.
9. Krajkovicova-Kudlackova M, Valachovicova C, Mislanova Z, Hudecova Sudstrova M, Ostatnikova D: Plasma concentration of selected anti-oxidants in autistic children and adolescents. Bratisl Lek Listy 2009, 110:247-250.

10. Al-Gadani Y, Al-Ansary A, Al-Attas O, Al-Ayadhi L: Oxidative stress andantioxidant status in Saudi autistic children. Clin Biochem 2009, 24:1032-1040.

11. Schopler E, Reichler RJ, Rochen Renner B: The childhood autism rating scale. Los Angeles: Western Psychology Services; 2007.

12. Castelloe P, Dawson G: Sub classification of children with autism and pervasive developmental disorder: A questionnaire based on Wing's subgrouping scheme. J Autism Dev Disord 1993, 23:229-241.

13. Constantino JN, Gruber CP: Social Responsiveness Scale. Los Angeles: Western Psychological Services; 2005.

14. Hye A, Lynham S, Thambisetty M, Causevic M, Campbell J, Byers HL, Hooper C, Rijsdijk F, Tabrizi SJ, Banner S, Shaw CE, Foy C, Poppe M, Archer N, Hamilton G, Powell J, Brown RG, Sham P, Ward M, Lovestone S: Proteome-based plasma biomarkers for Alzheimer's disease. Brain 2006, 129:3042-3050.

15. Magos L: Selective atomic-absorption determination of inorganic mercury and methylmercury in undigested biological samples. Analyst 1971, 96:847-853.

16. Miller DT, Paschal DC, Gunter EW, Stroud PE, D'Angelo J: Determination of blood lead with electrothermal atomic absorption using a L'vov platform and matrix modifier. Analyst 1987, 112:1701-1704.

17. Parsons PJ, Slavin W: A rapid Zeeman graphite furnace atomic absorption spectrometric method for the determination of lead in blood. Spectrochim Acta 1993, 48B(6/7):925-939.

18. Driskell WJ, Neese WJ, Bryant CC, Bashor MM: Measurement of vitamin A and vitamin $\mathrm{E}$ in human serum by high performance liquid chromatography. J Chromatogr 1982, 231:439-444.

19. Nigg JT, Nikolas M, Mark Knottnerus G, Cavanagh K, Friderici K: Confirmation and extension of association of blood lead with attentiondeficit/ hyperactivity disorder (ADHD) and ADHD symptom domains at population-typical exposure levels. J Child Psychol Psychiatry 2010, 51:58-65.

20. Surkan PJ, Zhang A, Trachtenberg F, Daniel DB, McKinlay S, Bellinger DC: Neuropsychological function in children with blood lead levels $<10$ microg/dL. Neurotoxicology 2007, 28:1170-1177.

21. Mazumdar M, Bellinger DC, Gregas M, Abanilla K, Bacic J, Needleman HL: Low-level environmental lead exposure in childhood and adult intellectual function: a follow-up study. Environ Health 2011, 10:24.

22. Cecil KM, Brubaker CJ, Adler CM, Dietrich KN, Altaye M, Egelhoff JC, Wessel S, Elangovan I, Hornung R, Jarvis K, Lanphear BP: Decreased brain volume in adults with childhood lead exposure. PLoS Med 2008, 5:e112.

23. Cottrell EC, Seckl JR: Prenatal stress, glucocorticoids and the programming of adult disease. Front Behav Neurosci 2009, 3:19.

24. Schneider JS, Kidd SK, Anderson DW: Influence of developmental lead exposure on expression of DNA methyltransferases and methyl cytosine-binding proteins in hippocampus. Toxicol Lett 2013, 217(1):75-81.

25. Rudenko A, Tsai LH: Epigenetic regulation in memory and cognitive disorders. Neuroscience 2013.

26. Depienne C, Moreno-De-Luca D, Heron D, Bouteiller D, Gennetier A, Delorme R, Chaste P, Siffroi JP, Chantot-Bastaraud S, Benyahia B, Rouillard TO, Nygren G, Kopp S, Johansson M, Rastam M, Burglen L, Leguern E, Verloes A, Leboyer M, Brice A, Gillberg C, Betancur C: Screening for genomic rearrangements and methylation abnormalities of the $15 q 11-q 13$ region in autism spectrum disorders. Biol Psychiatry 2009, 66(4):349-359.

27. Al-Yafee YA, Al-Ayadhi LY, Haq SH, El-Ansary AK: Novel metabolic biomarkers related to sulfur-dependent detoxification pathways in autistic patients of Saudi Arabia. BMC Neurol 2011, 11:139.

28. Hyman $\mathrm{MH}$ : The impact of mercury on human health and the environment. Altern Ther Health Med 2004, 10(6):70-75.

29. Blaurock-Busch E, Amin OR, Dessoki HH, Rabah T: Toxic metals and essential elements in hair and severity of symptoms among children with Autism. Maedica (Buchar) 2012, 7(1):38-48.

30. Takahashi $Y$, Tsuruta S, Honda A, Fujiwara Y, Satoh M, Yasutake A: Effect of dental amalgam on gene expression profiles in rat cerebrum, cerebellum, liver and kidney. J Toxicol Sci 2012, 37(3):663-666. 
31. Mania M, Wojciechowska-Mazurek M, Starska K, Rebeniak M, Postupolski J: Fish and seafood as a source of human exposure to methylmercury. Rocz Panstw Zakl Hig 2012, 63(3):257-264.

32. Aschner M, Ceccatelli S: Are neuropathological conditions relevant to ethyl mercury exposure? Neurotox Res 2010, 18(1):59-68.

33. Elsheshtawy E, Tobar S, Sherra K, Atallah S, Elkasaby R: Study of some biomarkers in hair of children with autism. Middle East Curr Psychiatry 2011, 18:6-10.

34. Adams JB, Audhya T, McDonough-Means S, Rubin RA, Quig D, Geis E, Gehn E, Loresto M, Mitchell J, Atwood S, Barnhouse S, Lee W: Toxicological status of children with autism vs. neurotypical children and the association with autism severity. Biol Trace Elem Res 2013, 151(2):171-180.

35. Marino MD, Bourdelat-Parks BN, Liles LC, Weinshenker D: Genetic reduction of noradrenergic function alters social memory and reduces aggression in mice. Behav Brain Res 2005, 161:197-203.

36. Stone JM, Morrison PD, Pilowsky LS: Glutamate and dopamine dysregulation in schizophrenia-a synthesis and selective review. J Psychopharmacol 2007, 21:440-452.

37. Makkonen I, Riikonen R, Kokki H, Airaksinen MM, Kuikka JT: Serotonin and dopamine transporter binding in children with autism determined by SPECT. Dev Med Child Neurol 2008, 50:593-597.

38. El-Ansary AK, Bacha AB, Ayahdi LY: Relationship between chronic lead toxicity and plasma neurotransmitters in autistic patients from Saudi Arabia. Clin Biochem 2011, 44:1116-1120.

39. Szkup-Jabłońska M, Karakiewicz B, Grochans E, Jurczak A, Zaremba-Pechmann L, Rotter I, Nowak-Starz G, Samochowiec J: The effects of lead level in the blood on social functioning in children with developmental disabilities. Psychiatr Pol 2011, 45(5):713-722.

40. Blaurock-Busch $E$, Amin OR, Rabah T: Heavy metals and trace elements in hair and urine of a sample of arab children with autistic spectrum disorder. Maedica 2011, 6:247-257.

41. ATSDR: Toxicological Profile for Lead (update). (Agency for Toxic Substances and Disease Registry). Atlanta, GA: U.S. Department of Health and Human Services; 1999.

42. Nevin R: How lead exposure relates to temporal changes in IQ, violent crime, and unwed pregnancy. Environ Res 2000, 83:1-22.

43. Geier DA, King PG, Sykes LK, Geier MR: A comprehensive review of mercury provoked autism. Indian J Med Res 2008, 128:383-411.

44. Vojdani A, Mumper E, Granpeesheh D, Mielke L, Traver D, Bock K, Hirani K, Neubrander J, Woeller KN, O'Hara N, Usman A, Schneider C, Hebroni F, Berookhim J, McCandless J: Low natural killer cell cytotoxic activity in autism: the role of glutathione, IL-2 and IL-15. J Neuroimmunol 2008, 205(1-2):148-154.

45. Geier DA, Kern J, Geier MA: A prospective study of oxidative stress biomarkers in autistic disorders. Electron J Appl Psychol Innov Autism 2009, 5:2-10.

46. Atkinson A, Epand RF, Epand RM: Tocopherols and tocotrienols in membranes: a critical review. Free Radic Biol Med 2007, 44:739-764

47. Zingg JM, Azzi A: Non-antioxidant activities of vitamin E. Curr Chem Med 2004, 11:1113-1133.

48. Azzi A: Molecular mechanism of alpha-tocopherol action. Free Radic Biol Med 2007, 43(1):16-21.

49. Herndon AC, Diguiseppi C, Johndon SL: Dose nutritional intake differs between children with autism spectrum disorder and children with typical development? Autism Dev Disord 2008, 6:341-349.

50. Kontush $\mathrm{KO}$, Schekatolina $\mathrm{A}$ : Vitamin $\mathrm{E}$ in neurodegenerative disorder: Alzheimers disease. Ann N Y Acad Sci 2004, 1031:249-262.

doi:10.1186/1744-9081-10-14

Cite this article as: Alabdali et al:: A key role for an impaired detoxification mechanism in the etiology and severity of autism spectrum disorders. Behavioral and Brain Functions 2014 10:14.

\section{Submit your next manuscript to BioMed Central and take full advantage of:}

- Convenient online submission

- Thorough peer review

- No space constraints or color figure charges

- Immediate publication on acceptance

- Inclusion in PubMed, CAS, Scopus and Google Scholar

- Research which is freely available for redistribution

Submit your manuscript at www.biomedcentral.com/submit 